\title{
Design of a Heat Sink for an Electronic Component in ABB Drive using Different Types of Fins
}

\author{
Hassan Khurshid ${ }^{1}$, Karthik Silaipillayarputhur ${ }^{2}$, Tawfiq Al Mughanam³ \\ ${ }^{1}$ Assistant Professor, Department of Mechanical Engineering, King Faisal University, KSA \\ ${ }^{2}$ Assistant Professor, Department of Mechanical Engineering, King Faisal University, KSA \\ ${ }^{3}$ Dept. Chair, Department of Mechanical Engineering, King Faisal University, KSA
}

\begin{abstract}
This paper considers an analytical approach in the design of a passive heat sink for an ABB electrical drive. The heat sink is intended to dissipate a certain amount of heat energy and to maintain the surface temperature of an electronic communication board at the prescribed temperature. The maximum size of the heat sink is known due to the existing space constraint. This paper details the step by step procedure in the development of a passive heat sink that functions based on the natural convection. Two commonly used fins such as rectangular plate fins and rectangular pins fins were considered for the project. A parametric study was considered wherein a relationship was developed between the convection heat transfer coefficient and the air flow. Likewise, the impact of convection heat transfer coefficient was seen on the rate of heat transfer and the fin geometry.
\end{abstract}

\section{Introduction}

Since the beginning of the manufacturing of computers, engineers were in pursuit to develop processors in order to increase the frequency to perform the arithmetic and logical operations quickly. However, there was a problem that whenever the processor speed was increased, heat energy produced by the processor also increased. This resulted in the damage of the processor so there was an increased need to design a heat sink that could do the desired operation with optimum efficiency. Heat sink is based on the principle of increasing the outer surface area to increase the heat transfer between the surface and the air in the surrounding.

Heat sink is a device that keeps a hot component such as a processor cool during its operation. There are two types of heat sink: active and passive heat sink. Active heat sinks use power and are usually a fan type or have some other peltier cooling device. Fans with ball-bearing motors are common that often have life longer than sleeve bearings. Sometimes these types of heat sinks are referred to as HSF, which is short for heat sink and fan. Passive heat sinks have no mechanical components. They are made of an aluminium-finned radiator that dissipates heat through convection. For passive heat sinks to work at their full capacity, it is recommended that there should be a steady airflow moving across the fins. Heat sink is commonly used in the electronic components such as computers, electrical drives, smart phones, and DVD player and in mechanical components such as refrigerators and pumps to provide proper heat transfer from the component to the surroundings.

Companies are constantly striving to find lighter, more conductive materials to make efficient heat sinks. They are not needed to be made from just one material. For example, some heat sink producers are bonding copper and aluminium together. The design consists mainly of aluminium (for its lightweight properties) surrounded by a copper plate (for its high rate of thermal conductivity). These are great -- in theory -- but if the copper doesn't bonded tightly with the aluminium, which is often the case in inexpensive heat sinks, the copper plate can do more harm than good.

Lots of work is there related to fins. Ibrahim et al. [1] investigated the effect of perforation shape or geometry on the heat transfer of perforated fins. The fluid and heat transfer properties of plate fins or normally heat sink were studied experimentally and numerically using CFD. The difference between experimental and numerical results was reported to be about $8 \%$ and $9 \%$ for temperature distributions when the power supplied are $150 \mathrm{~W}$ and $100 \mathrm{~W}$ respectively. Ghalambaz et al. [2] formulated a numerical method of a fluid structure interaction represented by an oscillating elastic fin attached to a hot vertical wall od a square cavity. The finite element Galerkin method with the aid of the Arbitrary Lagrangian-Eulerian (ALE) procedure was used in the numerical analysis. Campo and Celentano [3] addressed the potential heat transfer enhancement in a modified straight fin of rectangular profile with an enlarged round base compensated by a reduced round tip 
when compared against the standard straight fin of rectangular profile. It was reported that the maximum heat transfer enhancement granted by the modified straight fin with round base and round tip having smallto-moderate aspect ratios could reach a favorable $12 \%$ margin. Santosa et al. [4] investigated the air and refrigerant side heat transfer coefficients of finned tube $\mathrm{CO} 2$ gas coolers using computational fluid dynamics modelling. Bilen et al. [5] studied the effect of aluminium porous fins on heat transfer. Nusselt number, heat transfer enhancement ratio and heat transfer performance for three gap heights over pore fins $(\mathrm{C} / \mathrm{H}=0,0.5$ and 1$)$ as well as three longitudinal fin pitches $(\mathrm{Sx}=116,126$ and $136 \mathrm{~mm})$ were investigated for the range of $5000<\mathrm{Re}<35000$. Srikanth and Balaji [6] reported the results of an experimental investigation of the heat transfer performance of a phase change material (PCM) based composite 72 pin fin heat sink subjected to individual heat loading of 4 discrete heaters of equal area. The hotspots imposed by spatially non uniform heat flux were seen to have a considerable effect on the melting and solidification cycle and hence on the thermal performance of the heat sink. Wang et al. [7] studied local single-phase flow heat transfer downstream a single pin fin experimentally and numerically. Three distinct flow regimes, depending on the Reynolds number, were characterized, namely: laminar flow with steady wake, laminar flow with unsteady wake, and turbulent flow. Kharangate et al. [8] investigated heat transfer and pressure drop characteristics of a microfluidic cooling device with staggered pin-fin array arrangement with dimensions as follows: diameter $\mathrm{D}=46.5 \mu \mathrm{m}$; spacing, $\mathrm{S} \sim 100 \mu \mathrm{m}$; and height, $\mathrm{H} \sim 110 \mu \mathrm{m}$. Ibrahim et al. [9] presented a state-of-the-art review on various techniques of heat transfer enhancement in latent heat thermal energy storage (LHTES) systems. The paper discussed research gaps in the methods of heat transfer enhancement for LHTES systems and proposed some recommendations. Utilization of extended surfaces (by longitudinal fins) was investigated by development of a numerical model to study the performance of a triplex tube heat exchanger (TTHX) equipped with a PCM under simultaneous charging and discharging (SCD) by Joybari et al. [10].Governing equations were developed and numerically solved using ANSYS Fluent v16.2. Three conventional fin geometries and six developed fin configurations were compared based on the temperature, liquid fraction, and natural convection behavior under both SCD and non-SCD conditions.

\section{Nomenclature}

Tamp Ambient temperature $\left({ }^{\circ} \mathrm{C}\right)$.

$\mathrm{T}_{\mathrm{s}} \quad$ Temperature of surface $\left({ }^{\circ} \mathrm{C}\right)$.

$\Delta \mathrm{T}$ : Temperature difference $\left({ }^{\circ} \mathrm{C}\right)$.

As Area $\left(\mathrm{m}^{2}\right)$

D: Depth (m).

$\mathrm{V}$ : $\quad$ Velocity $(\mathrm{m} / \mathrm{s})$

w: Width (m).

t: $\quad$ Thickness (m).
K: Thermal conductivity (W/M.K).

$\sigma: \quad$ Stefan-Boltzmann constant $\left(\mathrm{W} / \mathrm{m}^{2} \cdot \mathrm{K}^{-4}\right)$.

$\beta$ : $\quad$ Coefficient of thermal expansion $\left(\mathrm{k}^{-1}\right)$.

Pr: Prantdl number.

GrD: Grashof number.

Nud: Nusselt number.

h: Conviction coefficient $\left(\mathrm{W} / \mathrm{m}^{2} \mathrm{~K}\right)$.

g: The gravity acceleration $\left(\mathrm{m} / \mathrm{s}^{2}\right)$.

v: Kinematic viscosity of air $\left(\mathrm{m}^{2} / \mathrm{s}\right)$.

\section{Analytical Approach}

This project considers the design of a heat sink for an electronic communication board in $\mathrm{ABB}$ drive. The component generates $300 \mathrm{~W}$ of heat that needs to be dissipated. The component must be maintained at a temperature of $80^{\circ} \mathrm{C}$ (Surface Temperature). The maintained temperature inside the drive is $35^{\circ} \mathrm{C}$. Based on the size of the electronic communication board, the heat sink's suggested size is $500 \times 300 \mathrm{~mm}$. Aluminium is used as the base and the fin material. This selection is mainly due to its ease of manufacture, availabilty, light weight, low cost and high thermal conductivity.

\subsection{Methodology}

In order to design the heat sink following methodolgy is used. Firstly, the coefficient of convection heat transfer $(\mathrm{h})$ is determined by calculating these dimensionless numbers: Grashof number (Gr), Nusselt number $(\mathrm{Nu})$, and Prandtl number $(\mathrm{Pr})$. The formulae used are taken from the heat transfer standard text [11]. Grashoff number is calculated by using this formula.

$$
\begin{gathered}
\text { Grashof number }=G r_{x}=\frac{g \cdot \beta \cdot x^{2} \cdot \Delta T}{v^{2}} \\
\beta=\frac{1}{T_{\text {avg }}}
\end{gathered}
$$

$\mathrm{T}_{\mathrm{avg}}$ is used to determine the fluid properties that are prescribed in [11].

$$
\begin{aligned}
& v=18.97 \times 10^{-6} \mathrm{~m}^{2} / \mathrm{s} \\
& \operatorname{Pr}=0.696 \\
& k=0.02896 \mathrm{~W} / \mathrm{mk}
\end{aligned}
$$

Once Grashoff number is determined, average Nussult number is calculated by employing

$$
\overline{N u}=0.59(G r . \operatorname{Pr})^{0.25}
$$

From Nusselt number, the heat transfer coefficient is found out by the following relationship:

$\left.\overline{N u}=\frac{h \times L}{k}=\right\rangle \frac{\overline{N u} \times k}{L}$

where: 


\section{$k=0.02896 \mathrm{w} / \mathrm{m} . K$}

$L=0.5 \mathrm{~m}$

The rate of heat transfer from the plate itself is given by:

$$
q=h A \Delta T
$$

To enhance (increase) the rate of heat transfer fins are used. Several fin profiles are available. To start with, straight rectangular fins with the following dimensions are chosen:

Length of fins: $30 \mathrm{~mm}=0.03 \mathrm{~m}$

Thickness of fin: $3 \mathrm{~mm}=0.003 \mathrm{~m}$

Depth of fins: $300 \mathrm{~mm}=0.3 \mathrm{~m}$

The basic calculation is to find out the number of fins but before doing that fin efficiency and the heat transfer from one such fin has to be determined. For fin efficiency it is needed to calculate the corrected length (based on the shape of fin), profile area and fin parameters. The formulae employed are given as [11]

Corrected length $=L_{c}=L+\frac{t}{2}$

Profile Area $=A_{m}=t . L_{c}$

$x$-axis $=>L_{c}{ }^{1.5}\left[\frac{h}{k \cdot A_{m}}\right]^{0.5}$

Fin efficiency can then be found out using the charts prescribed in [11].

Heat transfer from one fin is given as

$q_{\text {fin }}=\eta_{\text {fin }} \times A_{s}$, fin $\times \Delta T$

The number of fins required to dissipate $300 \mathrm{~W}$ of energy in plate fin is then determined by following relationship

$q_{\text {total }}=N \times q_{\text {fins }}+h[(l \times$ width $)-N(t \times$ depth $)] \Delta T$

It is also important to find out the spacing in between each fin. It can be calculated using these formulae [11]

Total space between fins $=L-($ no.of fins $\times t)$

And

$$
\text { space between two fins }=\frac{\text { total space between fins }}{\text { number of fins }-1}
$$

Rectangular pin fin with two different dimensions were also considered in this study:

\begin{tabular}{|l|l|l|l|}
\hline & Length & Thickness & Depth \\
\hline Case 1 & $30 \mathrm{~mm}$ & $5 \mathrm{~mm}$ & $5 \mathrm{~mm}$ \\
\hline Case 2 & $30 \mathrm{~mm}$ & $3 \mathrm{~mm}$ & $3 \mathrm{~mm}$ \\
\hline
\end{tabular}

For this type of fin the formula to determine the heat transfer from one fin is given as

$q_{\text {fin }}=\eta_{\text {fin }} \times\left(2 L_{c} \times\right.$ depth $) \times \Delta T$

Figure 1 and 2 show the three-dimensional model for the rectangular plate fins and rectangular pin fins.

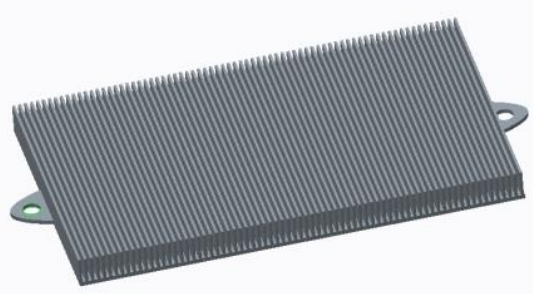

Figure 1: 3D rectangular plate fin heat sink

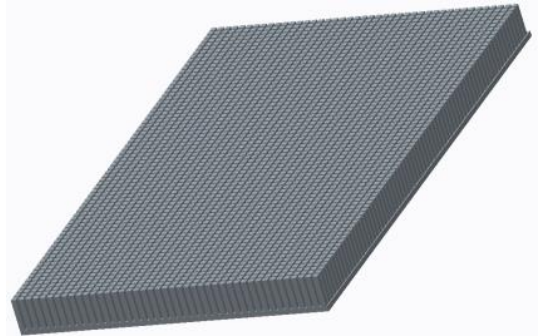

Figure 2: 3D rectangular pin fin heat sink

\section{Discussion}

Based on the analytical model, the number of fins required to remove $300 \mathrm{~W}$ are calculated and the results are summarized in table 1 as follows:

Table 1: Heat removed, no. of fins, and total number of fins for the three cases

\begin{tabular}{|l|c|c|c|c|}
\hline & $\begin{array}{c}\text { Dimensions in mm } \\
\mathrm{L} * \mathrm{~T} * \mathrm{D}\end{array}$ & $\begin{array}{c}\text { Heat removed from } \\
\text { one fin in } \mathrm{W}\end{array}$ & No. of fins & $\begin{array}{c}\text { Total Area of } \\
\text { fins }^{2} \mathrm{~mm}^{2}\end{array}$ \\
\hline Rectangular Plate fins & $30 \times 3 \times 300$ & 3.79 & 75 & 67500 \\
\hline Rectangular Pin fins & $30 \times 5 \times 5$ & 0.063 & 4639 & 115975 \\
\hline Rectangular Pin fins & $30 \times 3 \times 3$ & 0.037 & 7666 & 68994 \\
\hline
\end{tabular}

It is clear from the table that for the rectangular plate fin, the heat rate from one fin is $3.79 \mathrm{~W}$ and the total number of fins required to dissipate the heat and to maintain the temperature are 75 . Spacing between each fin is calculated as $3.7 \mathrm{~mm}$.

Same calculations are repeated for the two cases of rectangular pin fin. Heat transfer rate and number of fins are calculated. The total number of fins needed in both cases are 4639 fins $(t=5 \mathrm{~mm})$ and 7666 fins $(t=3$ $\mathrm{mm}$ ), respectively. It is obvious that as the thickness of the fin is decreased the number of fins required to dissipate the same amount of heat are increased.

A parametric study, to investigate the effect of change in the velocity (forced convection) on coefficient of heat transfer and the number of fins was also conducted. Figure 3 shows how the coefficient of heat transfer ( $h$ ) changes with the increase in the incoming velocity. The relationship between the air velocity and the convection heat transfer coefficient can be described as

$h=-0.0015 V^{2}+0.3748 V+4.9665$ 
Figure 4 indicates the effect of increasing velocity on the heat transfer from the fin. It is evident that by increasing the airflow (velocity) the heat transfer from the fin is enhanced.

Figure 5 describes the air velocity verses the no. of fins required to remove $300 \mathrm{~W}$ of energy. The number of fins decrease as the velocity of the air passing over the plate increases. This refers to the fact that forced convection, if possible, is more efficient means to dissipate the heat as compared to the natural convection heat transfer.

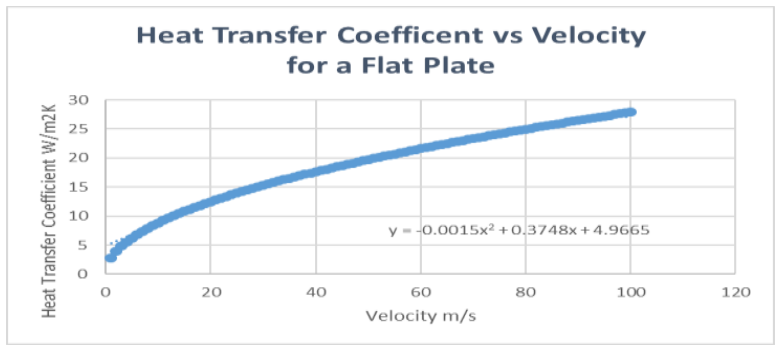

Figure 3: Heat transfer coefficient against the velocity for a flat plate.

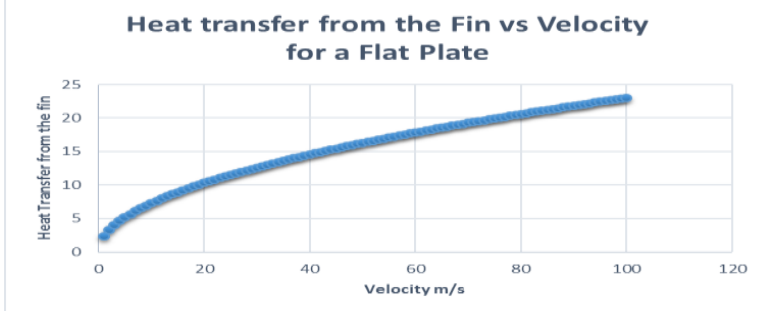

Figure 4: Heat transfer from the fin against the velocity for a flat plate.

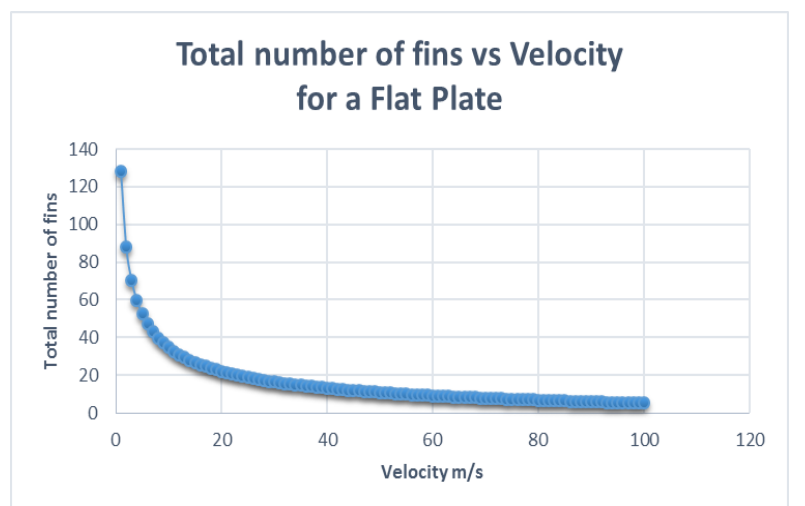

Figure 5: Total number of fins against the velocity for a flat plate.

\section{Conclusions}

The manuscript describes the development of a heat sink for an electronic communication board employed in an $\mathrm{ABB}$ electrical drive. The steps in the development of a passive heat sink are described in detail. Two conventional fin geometries were considered in this work. From the fundamental principles, increasing the number of fins enhances the rate of heat transfer. However, such an interpretation must be verified with experimentation as fin spacing affects the rate of heat transfer as well. Likewise, it was also seen that increasing the air velocity enhances heat transfer. Nevertheless, the maximum air velocity for a given application is dictated by the fan size and by the tolerable limits of the given system.

\section{References}

[1] Ibrahim, T. K., Mohammed, M. N., Mohammed, M. K., Najafi, G., Sidik, N. A. C., Basrawi, F., Abdalla, S. N., and Hoseini, S. S., Experimental stidy on the effect of perforations shapes on vertical heated fins performance under forced convection heat transfer, International Journal of Heat and Mass Transfer, Vol. 118, pp. 832-846, 2018.

[2] Ghalmbaz, M., Jamesahar, E., Ismael, M.A., and chamkha, A.J.,Fluid structure interaction stidy of natural convection heat transfer over a flexible oscillating fin in a square cavity, International Journal of Thermal Sciences, Vol. 111, pp. 256-273, 2017.

[3] Campo, A., and Celentano, D.J., Heat trasnfer enhancement in a modified straight fin of rectangular profile with enlarged round base and correlated reduced round tip, International Journal of thermal Sciences, Vol. 129, pp. 545-551, 2018.

[4] Santos, I.M.C., Gowreesunker, B.L., Tassou, S.A., Tsamos, K.M., and Ge, Y., Investigations into air and refrigerant side heat transfer coefficients of finned tube $\mathrm{CO}_{2}$ gas coolers, International Journal of Heat and Mass Transfer, Vol. 107, pp. 168-180, 2017.

[5] Bilen, K., Gok, S., Olcay, A.B., and Solmus, I., Investigation of the effect of aluminum porous fins on heat transfer, Energy, Vol. 138, pp. 1187-1198, 2017.

[6] Srikanth, R., and Balaji, C., Experimental investigation on the heat transfer performance of a PCM based pin fin heat sink with discrete heating, International Journal of Thermal Sciences, Vol. 111, pp. 188-203, 2017.

[7] Wang, Y.Y., Woodcock, J.H., and Peles, Y., Experimental and numerical study about local heat transfer in microchannel with a pin fin, International Journal of Heat and Mass Transfer, Vol. 121, pp. 534-546, 2018.

[8] Kharangate, C.R., Jung, K.W., Jung, S., Kong, D., Schaadt, J., Iyengar,M., Malone, C., Lee, H., Asheghi, and M., Goodson, K.E., Experimental investigation of embedded micropin-fins for single phase heat transfer and pressure drop, Journal of Electronic Packaging, Vol. 140 (2), 2018.

[9] Ibrahim, N.I., Al-Sulaiman, F.A., Rahman, S., Yilbas, B.S., and Sahin, A.Z., Heat transfer enhancement ofphase change materials for thermal energy storage applications: A critical review, Renewable and Sustainable Energy Reviews, Vol. 74, pp. 26-50, 2017. 
[10] Joybari, M.M., Haghighat, F., Seddegh, S., and AlAbidi, A.A., Heat transfer enhancement of phase change materials by fins under simultaneous charging and discharging, Energy Conversion and Management, Vol. 152, pp. 136-156, 2017.
[11] Incropera, F. P., \& DeWitt, D. P., Fundamentals of heat and mass transfer, New York: J. Wiley 